\title{
Vertigem, reabilitação vestibular e demanda social
}

A prevalência das disfunções vestibulares é alta e dar importância para uma assistência resolutiva deste problema é fundamental. Vários protocolos estão propostos e a personalização dos exercícios parece ser a estratégia mais fisiológica para o tratamento destas disfunções. O desconforto provocado pela vertigem, a limitação funcional e o aumento do risco de quedas em idosos são situações fundamentais para se considerar na prática clínica.

A prevalência dos distúrbios vestibulares varia de 10 a $30 \%$ na população geral ${ }^{1}$. Na população americana com mais de 40 anos de idade, a prevalência chega a mais de 35\%, crescendo conforme a idade, podendo chegar a quase $85 \%$ após 80 anos de idade.

Se transformarmos estes percentuais em números absolutos em nossas cidades, teremos uma considerável parcela da população predisposta a limitações funcionais, que podem ser graves e crônicas, além de idosos em risco de fraturas por quedas. Não apenas a população perde em qualidade de vida, mas o incremento do custo dentro dos sistemas de saúde advindos das fraturas pós-queda deve ser levado em consideração.

O tratamento fisioterapêutico dos distúrbios vestibulares já se encontra bem fundamentado na literatura mundial e nacional. As propostas iniciaram na década de 40 quando se propôs uma seqüência de exercícios para habituação do sistema vestibular, e chamou-se de Protocolo de Cawthorne e Cooksey. Desde então, inúmeros outros protocolos foram propostos e fundamentados nos princípios da neuroplasticidade como a habituação, adaptação e compensação.

A reabilitação vestibular é indicada para os diferentes distúrbios vestibulares, causadas pelos mais diversos fatores etiológicos e é baseada em exercícios terapêuticos. Atualmente se discutem abordagens diferenciadas entre os pacientes, baseada nas características individuais. Chamou-se este tipo de enfoque de "reabilitação vestibular personalizada".

Porém um tipo específico de vestibulopatia, a vertigem posicional paroxística benigna (VPPB), pode ser tratado de forma extremamente simples e eficiente através de manobras específicas ${ }^{2}$. A manobra de Epley, a manobra de Semont e a de Lempert são utilizadas como recursos padrão ouro para o tratamento deste distúrbio, conforme a especificidade do canal semicircular comprometido. Estas manobras são aplicadas individualmente, em duas ou três sessões, e melhoram totalmente a queixa, demonstrando favorável relação custo/efetividade ${ }^{3}$.

Neste número, a Revista de Neurociências apresenta um estudo de caso com quatro pacientes que foram tratados com manobras e exercícios para treino de equilíbrio e marcha. Como desfechos, o equilíbrio estático e dinâmico foi mensurado através de escalas funcionais ${ }^{4}$.

Neste estudo, o tratamento durou em média 7 meses e obteve 12,5\% de melhora nas escalas de Berg e Tinneti e redução em 1,26 segundos no tempo do teste Timed Get up and Go. Estes achados podem ser considerados discretos para pacientes com média de idade do estudo (47 anos), para os quais, na prática, poder-se-ia esperar uma melhora maior ${ }^{5}$. Entretanto, segundo as autoras, a melhora subjetiva descrita pelos pacientes foi total e seus resultados foram semelhantes a outros descritos na literatura.

A VPPB, por sua vez, é na maioria das vezes tratada por períodos muito curtos (menos de um mês). Alguns autores, no entanto, demonstraram que o treino do equilíbrio após as manobras traz benefícios adicionais e podem, sim, estender o tratamento por alguns meses $^{6}$.

O trabalho de Adriana Mazzucato e Ana Paula Borges leva-nos a perceber que todos os fisioterapeutas dispõem de ferramentas simples e usuais na sua prática clínica para tratar os mais variados tipos de disfunções vestibulares. A prática e a experiência clínica, aliada ao conhecimento das especificidades dos problemas, como sua localização e da melhor estratégia terapêutica permitirão a aquisição de resultados diferenciados.

Outro ponto forte do estudo foi o possível contato de estudantes com este perfil de pacientes, pois o mesmo foi realizado em uma clínica escola. Este fato desperta o interesse, facilita a disseminação do conhecimento e tende a beneficiar cada vez mais o grande número de doentes existente, carentes deste tipo de estratégia, tida hoje como a ideal, porém pouco difundida na prática.

\section{REFERÊNCIAS BIBLIOGRÁFICAS}

1.Neuhauser HK. Epidemiology of vertigo. Curr Opin Neurol 2007;20:40-6.

2.Teixeira LJ, Machado JNP. Manobras para o tratamento da vertigem posicional paroxística benigna: revisão sistemática da literatura. Rev Bras Otorinolaringol 2006;72:130-9.

3.Fife TD, Iverson DJ, Lempert T, Furman JM, Baloh RW, Tusa RJ, et al. Practice Parameter: Therapies for benign paroxysmal positional vertigo (an evidence-based review): Report of the Quality Standards Subcommittee of the American Academy of Neurology. Neurology 2008:70:2067-74.

4.Mazzucato A, Borges APO. Influência da reabilitação vestibular em indivíduos com desequilíbrio postural. Rev Neurocienc 2009:17:183-8. Teixeira LJ, Prado GF. Impacto da fisioterapia no tratamento da vertigem. Rev Neurocienc 2009;17:112-8.

6.Chang W-C, Yang Y-R, Hsu L-C, Chern C-M, Wang R-Y. Balance improvement in patients with benign paroxysmal positional vertigo. Clin Rehabil 2008:22:338-47. 